Alma Mater Studiorum - Università di Bologna DEPARTMENT OF ECONOMICS

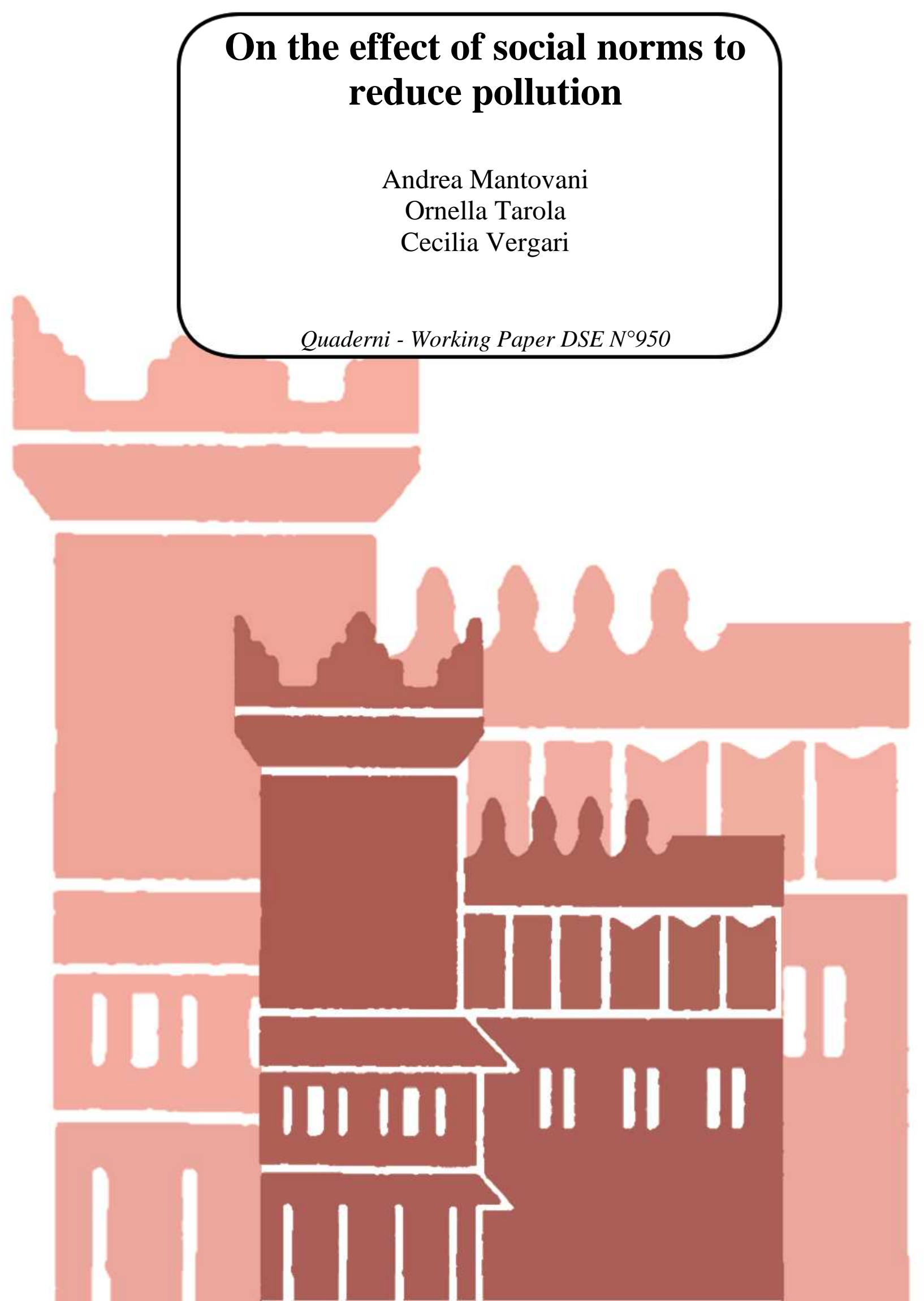




\title{
On the effect of social norms to reduce pollution*
}

\author{
Andrea Mantovani, ${ }^{\dagger}$ Ornella Tarola ${ }^{\ddagger}$ and Cecilia $\operatorname{Vergari}^{\S}$
}

June 16, 2014

\begin{abstract}
We analyse how market competition in a vertically differentiated polluting industry is affected by product variants that comply at different levels with "green" social norms. A green consumption behaviour is considered as a byword of good citizenship. Consumer preferences depend on a combination of hedonic quality and compliance with the norms. Assuming that the high hedonic quality variant complies less with the norms than the low hedonic quality one, we characterize the different equilibrium configurations, depending on the perceived intensity of such norms. Then, we focus on the role that institutions may have in using these norms to reduce pollution emissions.
\end{abstract}

Keywords: Social norms, Hedonic quality, environmental quality, relative preferences, vertical differentiation.

JEL Classification: D62, L13; H13.

"To secure her daughter a position on her high school cheerleading team, Wanda Webb Holloway solicited a man to kill the mother of her daughter's chief rival, hoping that the mother's death would distract the rival from the competition. In Japan, enough people work themselves to death that the culture has a name for this means of dying: karoshi. [...] ." (McAdams, 1992, p. 2)

\footnotetext{
${ }^{*}$ We are grateful to Luca Lambertini, Francisco Ruiz-Aliseda, and the audience at ERMES (Université Pantheon Assas, Paris II) and Pontificia Universidad de Chile for precious comments and discussion. The usual disclaimer applies.

${ }^{\dagger}$ Department of Economics, University of Bologna, Strada Maggiore 45, 40125 Bologna, Italy, and Barcelona Institute of Economics (IEB), C/ Tinent Coronel Valenzuela 1-11, 08034 Barcelona, Spain; email: a.mantovani@unibo.it.

${ }^{\ddagger}$ Department of Economics and Social Sciences, University of Rome "La Sapienza"; email: ornella.tarola@uniroma1.it.

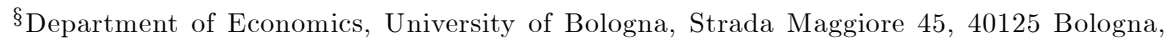
Italy, email: cecilia.vergari@unibo.it
} 


\section{Introduction}

Many are the situations in which people do not pursue an absolute end, but a relative position among peers. "Ms. Holloway sought for her daughter elevated status and popularity among her classmates, while the Japanese workers seek elevated rank and prestige among their coworkers. The lesson of these two examples is that for some, social position is an end literally worth killing or dying for." (McAdams, 1992, p. 3). Typically, such a social recognition is obtained through positional goods which enrich the buyer with some social/psychological benefits beyond the mere material value. ${ }^{1}$

In this paper, we first examine how the existence of positional concerns affects competition in a vertical differentiated industry in which producers pollute at different levels. In particular, we consider the existence of social norms that may induce consumers to prefer the less polluting product, although of lower intrinsic quality. Then, we draw policy implications by taking into account the possibility that the government may influence the penetration of such social norm.

In order to motivate our approach, we start by considering the positional content of environmentally friendly products vs. brown alternatives (Goldstein et al. 2008; Allcott, 2011). In recent years, people have become increasingly aware of the impact of their consumption choices on the environment. At large, every consumption decision may contribute to either protect or damage the environment, thereby affecting not only the quality of life of the consumer, but also of her family, friends, and colleagues.

When buying "green" products, people feel that they comply with a social norm for which such a green consumption behavior is a byword of good citizenship. As a consequence, an environmentally friendly product may contribute to satisfy the desire to stand out as a good citizen and of being socially worthy (Ostrom, 2000). At the opposite, when buying "brown" products, consumers may incur a social stigma as they fail to comply with the norm of responsible citizens. In other words, green consumerism helps reaching the status of good citizenship, while an opposite result may be obtained though the consumption of brown goods.

Moreover, the lower the pollution emission as compared to other products, the higher the contribution to the environmental protection and thus the social/psychological benefit derived by the compliance with the norm for the green consumer. Symmetrically, the social stigma is wider, the more polluting the good compared with the green product: the environmental quality gap between variant is thus a measure of the positive (or negative) contribution of people to the environmental protection. It is the product's relative position on

\footnotetext{
${ }^{1}$ This behavior is well described by the theory of conspicuous consumption in which consumer's utility partially depends on the comparison between the own consumption and that of others. Under conspicuous consumption, buyers are willing to pay a higher price for a functionally equivalent good in order to reveal their wealth and/or or other characteristics alike. Moreover, they can be induced to purchase either for invidious comparison, namely to distinguish themselves from the others, or for pecuniary emulation, namely to be considered as members of a group.
} 
the environmental quality ladder that defines the individual's relative position on the social ladder.

Rather interestingly, in spite of the increasing evidence about the environmental impacts of consumer's purchase decisions, there is also evidence of a gap between such green awareness and the actual consumption behavior. One of the main reasons is that brown goods are usually not only cheaper, but they still perform better than their green alternatives (Carrigan and Attalla, 2001, Gupta and Ogden 2009, Weatherell et al., 2003). A typical example is the car sector, in which combustible vehicles dominate electric or hybrid vehicles in terms of safety standard and pure engine performance. Based on intrinsic quality considerations, there would be no competition at all. However, the importance attached to the environmental performance may revert such conventional ranking. In spite of the neoclassical approach to utility-maximization, there can be a trade-off between utility derived from preferred characteristics of a product and the social pressure to buy "green" in a community. "If a consumer buys a product which lacks any environmental friendly characteristics, he might have a bad conscience because environmental awareness is expected from him. His environmental attitude is influenced by friends, parents, partners, or by the media..." (Conrad, 2005, p. 2).

These considerations constitute the two basic ingredients of the model developed hereafter. First of all, we argue that due to the existence of environmental social norms, green and brown products are perceived as positional. ${ }^{2}$ As immediate consequence, the benefit derived from consuming the green good (resp. the brown good) depends on its environmentally friendly (resp. unfriendly) quality relative to the brown (resp. green) product: the larger the environmental quality gap between goods, the larger the positional gap along the social ladder. Second, the social component of consumption can possibly be in conflict with the individual-rationality-based motive so that consumers hesitate between privileging either some intrinsic features of the good (like its performance) or its environmental quality.

In order to formalize the above evoked ingredients, we consider a vertically differentiated duopoly in which the pure performance of the product determines its hedonic quality. As in standard models of vertical differentiation, the high quality variant performs better than the other. However, the low quality variant is less polluting than the other, and this is perceived by consumers as a social benefit (Lombardini-Riipinen, 2005; García-Gallego and Georgantzís, 2009). On the contrary, when buying the high-but-brown quality, consumers incur a social stigma, as they increase the environment degradation thereby failing to comply with the norm.

We introduce both the social stigma and the social benefit in the utility function: they increase with the environmental quality gap between variants, given that the two variants comply differently with the social norm. This point deserves attention. When products are quality-differentiated, people define their

\footnotetext{
${ }^{2}$ Notice that in this approach, the positional content of goods immediately derives from the social norm: to the extent that a good complies (resp. does not) with the norm, it provides a social benefit (resp. social frustration).
} 
consumption choice taking into account the satisfaction derived from the intrinsic characteristics of the products, given by hedonic qualities and prices. Ceteris paribus, the higher the quality of its variant, the larger the market share. Here the shopping decisions contribute to define the social traits of an individual through a mechanism of social inclusion/exclusion: buying a green vehicle puts the driver among the green consumers, while distancing him from those who buy dirty cars. This social inclusion/exclusion mechanism is stronger, the wider the quality gap between variants.

We would like to stress that our paper has no direct relationship with current environmental regulations adopted by specific countries, being only concerned with the existence of a social norms shared among people. Take as an example the emissions standards set by the European Union for combustible vehicles. Although two different types of vehicles may comply with such standards, their emissions levels may not be the same. From a regulatory viewpoint both vehicles are "sufficiently" green and therefore do not incur any circulation restriction. However, from the consumer viewpoint the less pollutant vehicle is considered as the green one, and it entails a positive social image.

We capture this phenomenon by introducing relative preferences in the standard model of quality differentiation. In other words, we assume that the utility from consuming a variant is also depending on the environmental quality gap between this variant and the other available in the market. ${ }^{3}$ While this assumption enables to capture the social role of shopping in enhancing environment's protection, it makes the solution to the consumption dilemma between two variants - different in terms of both hedonic quality and pollution - far from being evident. Indeed, increasing the hedonic quality of a variant does not guarantee a priori an increase in its demand at equilibrium, as long as a higher performance is obtained at the expenses of the environment. Rather, if consumers are strongly environmentally concerned, it may happen that they prefer to buy low-but-green hedonic quality good, even if sold at the same price!

The introduction of relative preferences generates a trade-off between hedonic quality and environmental quality. The existence of such trade-off represents the building block of our theoretical model, and its solution will have interesting policy implications. We start by analyzing how such preferences affect the equilibrium market configurations while taking into account some specific market features. In particular, we develop the analysis in (i) low-income countries (or regions), where both the average income and the highest willingness to pay for the hedonic quality variant are rather low, and (ii) high income countries, where consumers are endowed with high average income. ${ }^{4}$ These two levels of

\footnotetext{
${ }^{3}$ In his pioneristic paper, Akerlof (1997) states the satisfaction of a consumer increases with the difference between the personal status and others' status. Later, Alexopoulos and Sapp (2006) and Reichmann (2006) analyze relative preferences from the firms standpoint. These preferences are also labeled "other-regarding preferences".

${ }^{4}$ The willingness to pay is usually proportional to the consumer's income (Gabszewicz and Thisse, 1979). In a different view, the analysis can be interpreted in terms of heterogeneity among consumers, namely the gap between the lowest and the highest willingness to pay for a good. When embracing this perspective, by keeping the density of consumers' distribution constant, the heterogeneity can be used as a proxy for the income dispersion in a country and
} 
analysis enable to identify some country-specific properties of the equilibrium configurations and to detail the role of institutions depending on the country where they act.

In the first part of the paper, we show that there are circumstances where the traditional assumption of rationality based-behavior may constitute a too drastic simplification of consumption decisions. This may have misleading implications at the equilibrium analysis. ${ }^{5}$ Indeed, the existence of a conflict between the value attributed to the hedonic quality and the positional satisfaction deriving from consuming an environmentally friendly good may change the equilibrium market configuration compared to the traditional setting of vertically differentiated goods. In particular, we prove that there exist circumstances in which the producer of the low-but-green variant quotes a higher price than the rival due to the perceived (and highly appreciated) superior environmental performance. Thus, at this duopoly equilibrium, a price switch is observed compared with the conventional wisdom that the high quality good is sold at a higher price than the competing variant. Furthermore, we find that, whenever the intensity of the relative preferences is sufficiently high, a market-monopolization effect takes place so that only the green firm is active on the market, the brown competitor being kicked out from the market. Nevertheless, at this monopoly equilibrium configuration, it may well happen that for extremely high intensity of relative preferences, the green monopolist extends the market coverage farther than what we typically observe in a vertically differentiated setting, thereby inducing a market-coverage effect.

In the second part of the paper we draw interesting policy considerations through a welfare analysis. More precisely, we evaluate how the intensity of these relative preferences may be affected by institutions that aim at reducing polluting emissions. In particular, we assume that the government can endorse some (relatively) costly environmental campaigns seeking to increase consumers' environmental awareness, thereby amplifying the social/psychological component derived from consuming the green variant. To this regard, we account for recent evidence gathered worldwide of an increasing trend of public authorities launching campaigns which advertise the detrimental effects on the environment of consumption habits. For example, "Generation Awake", the recent awareness-raising campaign created by the European Commission, includes a consumption guide to help understand and rank the impact on the environment of different products and daily habits. ${ }^{6}$ There are also other environmental education initiatives at national and regional level, like the "Cambia la lampadina" spot in 2010 developed in Italy by the Ministry of the Environment, comparing consumption of incandescent light bulbs versus low-energy consumption light bulbs.

thus enables to consider how the equilibrium configuration changes with the dispersion among consumers.

${ }^{5}$ Ben-Elhadj et al. (2014) analyse the implications of this assumption in a vertical differentiation setting.

${ }^{6}$ See http://www.generationawake.eu/en/ for details. 
We find that the effect of such campaigns magnifying the role of social norms can be welfare improving. Further, in some circumstances (which are proved to be country-specific), they may even enable the low-but-green quality producer to expand its market share to a further extent than in the typical equilibrium configuration arising in vertical differentiation. This happens when the social norm is so ingrained in the consumer's habit that she may refrain from buying the high-but-brown quality in order to avoid the social stigma coming from it. Reinforcing the social component of consumption, the policy maker may squeeze the brown producer's market to the extent that emissions coming from the brown good tend to zero. Interestingly, this positive effect of pollution emissions abatement is obtained while keeping in the market the polluting firm and thus preserving the competition in the market.

\section{Our paper in the literature}

Recently, an increasing attention has been devoted to the impact of environmental awareness on market equilibrium. ${ }^{7}$ However, to the best of our knowledge, we are the first to combine in a unified setting of vertical differentiation the notion of relative preferences and the possibility of a conflict between such preferences and traditional hedonic qualities. In this perspective, we complement the paper by Conrad (2005) and that by Ben Elhadj and Tarola (2014), thus contributing to this strand of the environmental literature.

Conrad (2005) considers the trade-off between the utility derived from the preferred characteristics of a product and the moral behavior of "buying green". ${ }^{8}$ He considers a horizontal differentiation setting to analyze a two stage game where firms define the environmental characteristic of goods in the first stage, thereby competing in price in the second stage. We share the view that environmental concerns may modify the traditional consumers' preferences and, accordingly, it should be directly incorporated into the utility function. Nevertheless, we depart from this model as our analysis is conceived in a vertically differentiated setting. We embrace the view that the environmental quality is perceived by consumers as a positive characteristic of the product. Therefore, they are willing to pay a higher price for the green good. ${ }^{9}$ Finally, far from Conrad (2005), we assume that both the social benefit and stigma increase with

\footnotetext{
${ }^{7}$ See Conrad, 2005; Eriksson, 2004; García-Gallego and Georgantzís, 2009; MoragaGonzalez and Padro-Fumero, 2002; Nyborg et al., 2006; Rodriguez-Ibeas, 2007; Ben Elhadj and Tarola, 2014, inter alia.

${ }^{8}$ More recently, Coad et al. (2009) consider the processes of adoption of proenvironmental innovations by individual consumers. They point out that as environmental protection is a public good, not all agents can be willing to preserve environment. In this view, they wonder whether the Government policy may thus intervene to sustain adoption of environmental innovations such as environmentally-friendly cars. Although they are mainly concerned with the notion of public good, their discussion on intrinsic motivation and environmental morale provides useful insights to our analysis.

${ }^{9}$ See Farhar and Houston, 1996; Green Gauge Report, 2000; Levin, 1990; Wasik, 1996; Lombardini-Riipinen, 2005, and García-Gallego and Georgantzís; 2009.
} 
the environmental quality gap between variants. ${ }^{10}$

Ben Elhadj and Tarola (2014) is instead developed in a vertically differentiated setting, like ours. Also, we are close to the authors in the approach of relative preferences as they formalize that people seek a relative position among peers and buy products also because of their social value. In their paper, the relative position of a buyer in the social ladder is depending on the relative position of the variant he/she buys along the quality ladder: the larger the quality gap between variants, the larger their positional gap along the quality ladder and consequently the gap between buyers along the social ladder. Still, they are only concerned with circumstances such that a variant is simultaneously of higher hedonic quality and more environmentally friendly than the alternative. Accordingly, it never arises a conflict for the consumer between the hedonic quality of a variant and the social image it can confer to him/her when defining his/her consumption choice. We complement their analysis by introducing this conflict into the utility function.

Finally, departing from both Conrad (2005) and Ben Elhadj and Tarola (2014), we analyse the role of institutions in affecting consumers' decisions by educational programs that somehow inform consumers about their choices' impact on the environment. By introducing this policy instrument, we broaden the scope for government intervention against global pollution, which is typically relegated by the literature to taxes and subsidies. ${ }^{11}$ In this vein, our paper is related with a recent literature supporting environmental/informative campaigns as a policy instrument to supplement and/or substitute traditional environmental policies like taxation. Two related papers are those by Sartzetakis et al. (2012) and Mantovani and Vergari (2014). In the first contribution the information campaign is always an efficient complementary policy because it reduces the asymmetry of information between consumers and manufacturers. In Mantovani and Vergari (2014), on the contrary, the efficiency of the two policy instruments, environmental campaign vs. taxation, crucially depends on consumers' environmental awareness. García-Gallego and Georgantzís (2009 and 2010) argue that increasing consumers' ecological awareness may be socially undesirable. In the first paper, this is due to possible changes in market structure; in the second paper, the desirability depends on the target of the campaign: increasing the willingness to pay of the most environmentally conscious consumers is privately profitable (but socially unprofitable), whereas increasing the willingness to pay of the least environmentally conscious consumers is socially profitable (but privately unprofitable). Their conclusion is that the state cannot rely on private campaigns. ${ }^{12}$

We contribute to the above literature by showing that these campaigns can be socially welfare improving when the realistic assumption of a conflict in

\footnotetext{
${ }^{10}$ We will discuss at lenght how our utility function differs from the one that he modeled.

${ }^{11}$ See, among others, Moraga-Gonzales and Padron-Fumero (2002), Lombardini-Riipinen (2005) and Deltas et al. (2013) for contributions on optimal tax policy with environmental quality.

${ }^{12}$ See for instance van der Made and Schoonbeek (2009) for the effects of an environmental campaign conducted by a private group.
} 
consumption behavior is introduced in the model.

The structure of the paper is as follows. In Section 3 we set up the model, in Section 4 we develop the country-specific equilibrium analysis. In Section 5 we compare the results for low income vs high income country. In Section 6 we provide the welfare analysis.

\section{The Model}

Consider a vertically differentiated market with two variants of the same good. Close in spirit to the models of vertical differentiation, we state that the performance of the variant $i$, with $i=L, H$ determines its intrinsic or hedonic quality $q_{i}$. Accordingly, $q_{H}>q_{L}$ : variant $H$ has a higher intrinsic quality than variant $L$. Nevertheless, as it generates polluting emissions per unit of production at some level $e_{H}=\phi q_{H}$, variant $H$ represents the brown good. At the opposite, variant $L$ is considered as green because its emissions $e_{L}$ are very low, namely $e_{L}=\phi q_{L}<e_{H}$. Accordingly, the environmental quality of $L$ turns out to be higher than that of $H$.

There is a continuum of consumers indexed by $\theta$ and uniformly distributed in the interval $[0, b]$ with density $\frac{1}{b}$. Keeping the traditional interpretation from vertical differentiation models, the parameter $\theta$ is proportional to the willingness to pay (henceforth WTP) for quality, so that $b$ denotes the maximal WTP among consumers. ${ }^{13}$ Each consumer can buy either one unit of good $H$ or one unit of good $L$ or not buying at all.

Whenever a vertically differentiated setting is used to analyse an environmental problem, it is generally assumed that products otherwise identical differ in their emissions so that the environmental quality represents the only source of differentiation (Moraga-Gonzales and Fumero 2002, Lombardini 2005, and García-Gallego and Georgantzís 2009, Ben Elhadj and Tarola, 2014). Here, we assume that there are two sources of differentiation: the hedonic quality $q_{i}$ and the environmental quality $e_{i}$ and these forces are conflicting. In particular, we assume that consumers display hedonic preferences in that they care about the hedonic quality or pure performance of the good they consume. Nevertheless, they feel that by buying brown goods they can be perceived among peers as bad citizens. At the opposite, buying green goods may provide a social benefit in that they are perceived as responsible citizens. So, they feel socially/psychologically frustrated (resp. satisfied) when consuming the brown good (resp. green good). As the source of this feeling is social and/or psychological, both the frustration and the satisfaction increase with the environmental quality gap between variants. Indeed, the lower the emissions coming from variant $i$ compared with variant $j$, with $i \neq j$, the more significant the contribution to the environment from consumers buying $q_{i}$ and thus the better their social image. On the contrary, the more polluting variant $i$ w.r.t variant $j$, the more detrimental the behavior of consumers buying this variant $i$ and so the more blameworthy their

\footnotetext{
${ }^{13}$ Under the assumption on density, the population of consumers is always constant. See on this Garcia-Gallego and Georgantzis (2009).
} 
image. It is worth noting that, at the opposite, from a social welfare viewpoint, the relative environmental quality of a variant would not play any role, being rather the absolute level of emissions $e_{L}$ and $e_{H}$, the reference point of a social planner.

In order to capture the role of these feelings, we assume that the utility from consumption is affected by both the variant's hedonic quality $q_{i}$ and the environmental quality gap between variants $\left(e_{H}-e_{L}\right)$. Formally, the indirect utility of consumer type $\theta$ writes as:

$$
U(\theta)=\left\{\begin{array}{c}
\theta q_{H}-p_{H}-\gamma\left(e_{H}-e_{L}\right), \text { if she buys the high quality good, } \\
\theta q_{L}-p_{L}+\gamma\left(e_{H}-e_{L}\right), \text { if she buys the low quality good, } \\
0, \text { if she refrains from buying. }
\end{array}\right.
$$

We add to the traditional component of the indirect utility function $\left(\theta q_{i}-p_{i}\right)$ a further ingredient, namely $\gamma\left(e_{H}-e_{L}\right)$ with $i \neq j$, such that the utility of buying a variant can be magnified (in the case when $\gamma\left(e_{H}-e_{L}\right)$ is added to the traditional terms) or rather decreased (when $-\gamma\left(e_{H}-e_{L}\right)$ is subtracted) by the environmental characteristics of the variant $i$ compared with the alternative $j$. So, when considering the term $\left|\gamma\left(e_{H}-e_{L}\right)\right|$, it is not the level of emissions per se to determine the utility of consuming a variant. Rather, as both the green and the brown variants are intended here as positional goods, it is the relative pollution coming from them to affect consumers' utility. This component of the utility function immediately derives from the relative preferences approach, where the utility of an outcome for a player in a game depends on player $i$ 's own payoff compared with the others made available in the market. ${ }^{14}$ In the perspective of relative preferences, the parameter $\gamma$, with $\gamma \geq 0$ measures the intensity of the relative dimension of consumption: ${ }^{15}$ the higher $\gamma$, the stronger the relative (or social) preferences with respect to the hedonic ones. ${ }^{16}$ For sake of simplicity and without any loss of generality, we can assume that $\phi=1 .{ }^{17}$

From the above formulation of the utility function, taking into account that $\left(e_{H}-e_{L}\right)=\left(q_{H}-q_{L}\right)$, the consumer indifferent between buying the low quality good and not buying at all is:

$$
\theta_{L}=\gamma+\frac{p_{L}-\gamma q_{H}}{q_{L}}=\frac{p_{L}-\gamma\left(q_{H}-q_{L}\right)}{q_{L}} .
$$

The consumer indifferent between buying the low quality good and the high

\footnotetext{
${ }^{14}$ See Ben Elhadi and Tarola (2014) for a deep discussion of this approach and its possible application to the environment.

${ }^{15}$ In our work, we use the terms social and relative as synomimous as both of them recall that consumption has a social dimension and as a such the resulting satisfaction also depends on the characteristics of the community where it takes place.

${ }^{16}$ The extreme case $\gamma=0$ reduces the model to the traditional vertical differentiation framework with hedonic preferences as unique drivers for buying.

${ }^{17}$ Of course, we could also state that $\phi>0$ without normalizing the parameter to 1 . However, this assumption would not bring any further insight to the model while making the welfare analysis by far more cumbersome.
} 
quality good is:

$$
\theta_{H}=2 \gamma+\frac{p_{H}-p_{L}}{q_{H}-q_{L}}=\frac{p_{H}-p_{L}+2 \gamma\left(q_{H}-q_{L}\right)}{q_{H}-q_{L}} .
$$

Note that, given prices, the market share of $L$ increases in $\gamma$. Indeed, ceteris paribus, the consumer that is indifferent between not buying at all and buying the low quality $\left(\theta_{L}\right)$ moves to the left due to $\gamma$, while the one indifferent between buying the low quality and the high quality $\left(\theta_{H}\right)$ moves to the right. Note also that due to the social component of consumption, even though the lower bound of the market is zero, the market can be covered a priori. Typically, in a vertically differentiated model, whenever the lowest willingness to pay is 0 , the market can never be covered. As firms are not allowed to price discriminate, they should quote a nil price for meeting the marginal consumer $\theta=0$, as this latter would get a non positive utility from consuming at some positive price. Accordingly, either they would get zero market share at a positive price, or a positive market share at zero price. In either case, the equilibrium profits would be zero. Here, on the contrary, consumer of type $\theta=0$ can have a positive utility from buying $L$ if $\gamma\left(q_{H}-q_{L}\right)>p_{L}$. Thus, it can be profitable for the green producer to cover the market at equilibrium, thereby serving even the consumer with the lowest willingness to pay.

We assume that profit functions of firm $H$ and $L$ write, respectively:

$$
\begin{aligned}
\pi_{H} & =x_{H} \cdot p_{H}, \\
\pi_{L} & =\left(p_{L}-c\right) x_{L} .
\end{aligned}
$$

with $x_{i}$ denoting the demand faced by firm $i$, and $c>0$ is the cost per unit of green production. In the above formulation, it is implicitly stated that production costs for firms only come from producing an environmentally friendly good. Otherwise, one could imagine that there exists a cost function $c_{i}=h_{i}+E_{i}$ where $h_{i}$ denotes the hedonic-quality specific cost borne by firm $i$, with $h_{H}>h_{L}$ and $E_{i}$ the environmental quality specific cost, with $E_{H}<E_{L} \cdot{ }^{18}$ As it is reasonable that $h_{H}>h_{L}$ always holds, the only way to get $c_{H}<c_{L}$ is to assume that $\left(E_{L}-E_{H}\right)>\left(h_{H}-h_{L}\right)$. Without any loss of generality, we can write $c_{L}>c_{H}=0 .{ }^{19}$

Before going through the possible equilibria, we make the following assumption that holds throughout the paper.

\section{Assumption 1}

\footnotetext{
${ }^{18}$ Of course, the case when $c_{H}>c_{L}$ has been largely treated in the literature on vertical differentiation (Cremer and Thisse 1994). Thus, we disregard it.

${ }^{19}$ One may wonder why we do not introduce some fixed costs to capture the role of green technologies in production. Admittedly, when the quality is mainly related to investments in new technologies or in $\mathrm{R} \& \mathrm{D}$, then the assumption of fixed quality-specific costs can be reasonable. Still, a fixed cost does not affect a price game: when competing in price, a fixed cost has already been sunk and accordingly it is neglected when computing the best reply functions of firms.
} 


$$
b>\underline{b} \equiv \frac{c\left(2 q_{H}-q_{L}\right)}{q_{L}\left(q_{H}-q_{L}\right)} .
$$

Assumption 1 ensures a sufficiently large consumers' heterogeneity and it will help reducing the conditions that we have to take into account for an equilibrium to exist. ${ }^{20}$

We develop the analysis considering in turn two different scenarios, depending on the values of the parameter $b$. To this aim, we consider the following threshold value of $b:^{21}$

$$
\widetilde{b} \equiv \frac{c q_{H}}{\left(q_{H}-q_{L}\right)^{2}}
$$

First, we consider that $b<\tilde{b}$, thereby moving to the alternative case with $b>\tilde{b}$. In the seminal paper on vertical differentiation by Gabszewicz and Thisse (1979), the parameter $b$ representing the willingness to pay for a variant is linked to the net income at disposal of consumers: consumers with the highest willingness to pay are those having highest per-capita income. Borrowing this interpretation, we can develop a market-specific analysis thereby identifying how this market feature affects the equilibrium configuration. In particular, when assuming that $b<\tilde{b}$, one can imagine that the equilibrium analysis is set for low-income countries (or regions), namely countries with a low income dispersion and low average income. At the opposite, when $b>\tilde{b}$ the analysis is performed for high-income countries, namely incomes with high average per capita income.

\section{The equilibrium analysis}

We will show in the following that, depending on the parameters' values, different market equilibrium configurations may arise. In order to solve the model, we compute the price equilibrium candidates corresponding to each market configuration and provide the parameter constellations for which candidates effectively yield the corresponding market outcomes. ${ }^{22}$

\subsection{Low-income countries}

Let us first consider the case where $b \in[b, \tilde{b}]$, thereby focusing on low-average per capita income. Typically, in a vertical differentiated setting, absent production costs, there is always room in the market for two firms if the market is not a natural duopoly. ${ }^{23}$ Further, when the lowest willingness to pay in the market is equal to zero, firms never find it profitable to cover the market. Accordingly, a

\footnotetext{
${ }^{20}$ Removing such an assumption does not change the main results of our paper.

${ }^{21}$ In the following section we will clarify where does this value come from.

${ }^{22}$ This is standard in models of vertical differentation. See Wauthy (1996) for more details.

${ }^{23}$ The upper bound to the number of firms which can coexist at equilibrium with positive market share and positive equilibrium prices has nothing to do with costs and only depends on pattern of tastes and willingness to pay distribution. In particular, given a population of consumers, identified by the parameter $\theta \in[\alpha, \beta], 0 \leq \alpha<\beta$ the upper bound to number of firms is 2 so that the market is a natural duopoly iff $\frac{\alpha}{\beta} \in\left[\frac{1}{4}, \frac{1}{2}\right]$.
} 
natural entry point for the analysis is assuming that both goods are in the market and that the market is uncovered. In this industry configuration, demands are defined as $x_{L}=\theta_{H}-\theta_{L}$ and $x_{H}=b-\theta_{H}$. Given the profit functions of firm $H$ and firm $L$, respectively

$$
\begin{aligned}
\pi_{H} & =x_{H} \cdot p_{H} \\
\pi_{L} & =\left(p_{L}-c\right) x_{L},
\end{aligned}
$$

the pair of candidate equilibrium prices can be easily obtained:

$$
\begin{aligned}
p_{L}^{*} & =\frac{2 c q_{H}+\left(q_{H}-q_{L}\right)\left(2 \gamma q_{H}+b q_{L}\right)}{4 q_{H}-q_{L}} \\
p_{H}^{*} & =\frac{c q_{H}+\left(q_{H}-q_{L}\right)\left[2 b q_{H}-\gamma\left(3 q_{H}-q_{L}\right)\right]}{4 q_{H}-q_{L}} .
\end{aligned}
$$

Formally, for this candidate to be an equilibrium, we need to verify that both prices are positive and that the low quality price $p_{L}$ is higher than marginal cost, namely $p_{H}^{*}>0, p_{L}^{*}>c$. Moreover, we have to verify that the market is uncovered, and that both goods have positive demands: $0<\theta_{L}<\theta_{H}<b$. From algebraic manipulations we find that Assumption 1 suffices to guarantee that the candidate equilibrium price of the low quality variant is higher than the marginal production cost $c$, namely $p_{L}^{*}>c$. Also, we find that in $b \in[b, \tilde{b}]$ there is room for both firms to be active in the market whenever the intensity of relative preferences $\gamma$ is sufficiently weak. In particular, it holds that

$$
\begin{aligned}
& \theta_{H}^{*}<b \Longleftrightarrow \gamma<\bar{\gamma} \equiv \frac{q_{H}\left[c+2 b\left(q_{H}-q_{L}\right)\right]}{3 q_{H}^{2}-4 q_{H} q_{L}+q_{L}^{2}}, \text { and } \\
& \theta_{L}^{*}>0 \Longleftrightarrow \gamma<\widehat{\gamma} \equiv \frac{2 c q_{H}+b\left(q_{H}-q_{L}\right) q_{L}}{2 q_{H}^{2}-3 q_{H} q_{L}+q_{L}^{2}} .
\end{aligned}
$$

It follows that both the consumer that is indifferent between not buying and buying the low quality good $\theta_{L}^{*}$, as well as the one indifferent between buying the low quality variant and the high quality alternative $\theta_{H}^{*}$ are in the market. Also, comparing $\theta_{H}^{*}$ and $\theta_{L}^{*}$, we find that:

$$
\begin{aligned}
\theta_{L}^{*} & =\frac{\left(2 c q_{H}+b q_{H} q_{L}+3 \gamma q_{H} q_{L}-b q_{L}^{2}-2 \gamma q_{H}^{2}-\gamma q_{L}^{2}\right)}{\left(4 q_{H}-q_{L}\right) q_{L}}, \\
\theta_{H}^{*} & =\frac{\left(2 b q_{H}^{2}-3 b q_{H} q_{L}-4 \gamma q_{H} q_{L}-c q_{H}+b q_{L}^{2}+3 \gamma q_{H}^{2}+\gamma q_{L}^{2}\right)}{\left(q_{L}-4 q_{H}\right)\left(q_{L}-q_{H}\right)}, \\
\theta_{H}^{*}-\theta_{L}^{*} & =\frac{\left(c q_{L}-2 c q_{H}+b q_{H} q_{L}-2 \gamma q_{H} q_{L}-b q_{L}^{2}+2 \gamma q_{H}^{2}\right) q_{H}}{\left(q_{L}-q_{H}\right)\left(q_{L}-4 q_{H}\right) q_{L}}
\end{aligned}
$$

where, the denominator of $\left(\theta_{H}^{*}-\theta_{L}^{*}\right)$ is positive, while the numerator is increasing in $\gamma$ and nil at $\gamma>\check{\gamma} \equiv \frac{\left(2 c q_{H}-c q_{L}-b q_{H} q_{L}+b q_{L}^{2}\right)}{2 q_{H}^{2}-2 q_{H} q_{L}}$. As $\check{\gamma}$ is decreasing in $b$ and nil at $b>\underline{b}$, we can conclude that for any $b>\underline{b}$, the threshold value $\check{\gamma}<0$, so that 
the inequality $\gamma>\check{\gamma}$ is always satisfied. This proves that whenever $b>\underline{b}$, then $\theta_{H}^{*}>\theta_{L}^{*}$. Thus, both firms have positive market share at equilibrium with firm $H$ serving consumers with higher WTP, while firm $L$ those having lower WTP, as in the traditional setting. Further, for any $\gamma<\bar{\gamma}$, the inequality $p_{H}^{*}>0$ is satisfied. Finally, we find that $\widehat{\gamma}>\bar{\gamma} \Longleftrightarrow b<\widetilde{b}$. We can summarize the above findings in the following Lemma:

Lemma 1 In the range where $b \in[\underline{b}, \tilde{b}]$, the conditions $0<\theta_{L}^{*}<\theta_{H}^{*}<b$ and $p_{H}^{*}>0, p_{L}^{*}>c$ hold whenever $\gamma<\bar{\gamma}$.

Notice, however, that contrary to what it is traditionally observed in a vertically differentiated setting, here the equilibrium price of the low hedonic quality variant $p_{L}^{*}$ can be higher than the price $p_{H}^{*}$ : indeed, it may well happen that the green nature of the variants is valued by consumers more than their performance. Ceteris paribus, this is the case when the intensity of social preferences $\gamma$ is rather high. Formally:

$$
p_{L}^{*} \gtrless p_{H}^{*} \Longleftrightarrow \gamma \gtrless \widetilde{\gamma} \equiv \frac{2 b q_{H}^{2}-3 b q_{H} q_{L}-c q_{H}+b q_{L}^{2}}{\left(q_{H}-q_{L}\right)\left(5 q_{H}-q_{L}\right)} .
$$

It is worth remarking that the property that $p_{L}^{*}>p_{H}^{*}$ is never met when consumers are not faced with the dilemma between hedonic quality and social/psychological driver. In the case when there is only a driver of consumption so that the preferences write as in the traditional setting of vertical differentiation, the equilibrium price of the high quality variant is always higher than the low quality price, whatever the source of the quality gap.

In order to characterize the equilibrium configurations in the range where $b \in[\underline{b}, \widetilde{b}]$, it suffices to show that the relevant $\gamma$-thresholds can be ranked as

$$
\widetilde{\gamma}<\bar{\gamma}<\widehat{\gamma} \text { whenever } b \in[\underline{b}, \widetilde{b}]
$$

Indeed, simple algebra reveals that $\widetilde{\gamma} \in(0, \bar{\gamma})$, and that:

$$
\widehat{\gamma}<\widetilde{\gamma} \Longleftrightarrow b>\widehat{b} \equiv \frac{3 c q_{H}}{q_{H}^{2}-3 q_{H} q_{L}+2 q_{L}^{2}}
$$

with $\widehat{b}>\widetilde{b}$. Accordingly, we can immediately conclude that whenever the intensity of relative preferences is sufficiently low, namely $\gamma<\bar{\gamma}$ (where $\bar{\gamma}<\widehat{\gamma}$ ), the existence of these preferences in the range $b \in[\underline{b}, \widetilde{b}]$ does not alter the market structure compared to the traditional vertically differentiated setting. Indeed, in spite of the social component of consumption, both firms can be active at equilibrium. However, it can determine a switch in the equilibrium price configuration. In particular, we find that whenever $\gamma \in(\widetilde{\gamma}, \bar{\gamma})$, the equilibrium price of the low quality variant turns out to be higher than the one of the high quality alternative, namely $p_{L}^{*}>p_{H}^{*}$. We say that a price switch effect takes place. Otherwise, whenever $\gamma<\widetilde{\gamma}$, then the traditional finding with $p_{L}^{*}<p_{H}^{*}$ holds. So, we state that: 
Proposition 1 Whenever $b \in[\underline{b}, \widetilde{b}]$ the unique equilibrium is a duopoly with both producers in the market for any $\gamma \in[0, \bar{\gamma}]$. Further, at equilibrium, in this range, if $\gamma \in(\widetilde{\gamma}, \bar{\gamma})$ the social component of consumption is so strong that the low quality firm can quote a price higher than that quoted by the brown rival, namely $p_{L}^{*}>p_{H}^{*}$.

It follows from that whenever the amount of the "brown-penalty/ greenreward" is not very significant, namely $\gamma<\bar{\gamma}$, both firms can sell their variant at equilibrium. In this range of $\gamma$ values, the traditional mechanisms of competition between firms taking place in a vertically differentiated market are not modified so that at the duopoly equilibrium, the market is uncovered. Nevertheless, contrary to the traditional finding holding in vertical differentiation where the price of the low quality variant is always lower than the one of the high quality product, the existence of $\gamma$ can determine a switch in the ranking of equilibrium prices so that the low quality firm can charge a higher price than the high quality rival. It is worth noting that, the higher the threshold value $\widetilde{\gamma}$, the higher is $b$ : the set of $\gamma$-parameters where the traditional prices structure holds (so that $p_{H}^{*}>p_{L}^{*}$ ) becomes larger, the more heterogeneous the market is. The economic intuition underlying the relation between $\widetilde{\gamma}$ and $b$ goes as follows. The higher is $b$, the higher the price which can be quoted at equilibrium by both firms. Indeed, absent any social driver of consumption, the higher is $b$ the more significant is the heterogeneity in the market and thus the less stringent is the price competition between firms; further the higher is $b$, the higher is the maximal WTP of consumers for the hedonic quality. The parameter $\gamma$ represents at the opposite the sensitiveness of consumers to the environmental protection: the higher is $\gamma$, the more relevant for consumers is the relative environmental quality of any variant $i$ and accordingly the higher (resp. the lower) is the price of the green variant (resp. the brown variant). Thus, given $b$, for $\gamma$ sufficiently high, consumers privilege the environmentally friendly nature of goods with respect to the hedonic quality, and possibly pay a higher price for the green good than for the brown, in spite of the hedonic quality gap between variants. On the contrary, given $\gamma$, whenever $b$ is rather high, the hedonic quality of variant $H$ is strongly valued by consumers which accordingly may be willing to pay a higher price for this variant than for the alternative product $L$, in spite of the environmental quality gap between them. In this case, the inequality $p_{H}^{*}>p_{L}^{*}$ holds. As immediate consequence, the higher the parameter $b$, the larger the set of $\gamma$-values such that this typical prices' structure $p_{H}^{*}>p_{L}^{*}$ is still met.

We next consider the case where $\gamma>\bar{\gamma}$ in the range where $b \in[\underline{b}, \widetilde{b}]$. While in the case when $\gamma<\bar{\gamma}$, there is still room in the market for both producers, this is no longer true whenever $\gamma \geq \bar{\gamma}$. In particular, from (7), we know that the condition for $\theta_{H}^{*}<b$ (or $p_{H}^{*}>0$ ) is that $\gamma$ is sufficiently low, namely $\gamma<\bar{\gamma}$. In the range of $\gamma$-parameters where $\gamma \geq \bar{\gamma}$, the high-quality firm is so strongly penalized by its brown nature that it can no longer be active in the market and $p_{H}^{*}=0$. As a consequence, the low quality producer is now a monopolist. Notice that, this threshold value $\bar{\gamma}$ is increasing in $b$ : the higher is $b$, the larger is the 
set of $\gamma$ parameters such that both producers can stay active in the market and the smaller is the set of $\gamma$-values where a monopoly equilibrium is observed. In this monopoly setting, the indifferent consumer $\theta_{L}$ is defined again by (1). However, the demand for the good $L$ is now given by $x_{L}=b-\max \left\{0, \theta_{L}^{M}\right\}$. Superscript $M$ refers to the monopoly case. From standard computations, we find that the equilibrium monopoly price is: ${ }^{24}$

$$
p_{L}^{M}=\frac{1}{2}\left[c+\gamma\left(q_{H}-q_{L}\right)+b q_{L}\right]
$$

At this monopoly equilibrium, the market can be either uncovered (namely $0<\theta_{L}^{M}<b$ ) or covered (namely $\theta_{L}^{M}<0<b$ ), depending on the intensity of $\gamma$. In particular:

Lemma 2 In the range where $b \in[\underline{b}, \tilde{b}]$, the condition $0<\theta_{L}^{M}<b$ holds for any $\gamma \in\left[\bar{\gamma}, \gamma_{M}\right]$, where $\gamma_{M} \equiv \frac{c+b q_{L}}{q_{H}-q_{L}}$. On the contrary, $\theta_{L}^{M} \leq 0<b$ holds whenever $\gamma>\gamma_{M}$.

Proof. Algebraic calculations reveal that: (i) $\theta_{L}^{M}>0 \Longleftrightarrow \gamma<\gamma_{M}$, and $\gamma_{M}>\bar{\gamma}$ in the relevant interval region $b \in[\underline{b}, \widetilde{b}]$. Also, (ii) $b>\theta_{L}^{M}$ when $\gamma>\frac{c-b q_{L}}{q_{H}-q_{L}}$. As $\bar{\gamma}>\frac{c-b q_{L}}{q_{H}-q_{L}}$, then the condition such that $b>\theta_{L}^{M}$ always holds when $\gamma>\bar{\gamma}$.

The economic intuition of the above Lemma goes as follows. Whenever the social dimension of consumption is not sufficiently strong, then it is not profitable for the green producer to cover the market. The reverse holds when the intensity of relative preferences is high, namely $\gamma>\gamma_{M}$ : in this circumstance, the WTP of the marginal consumer is so high to induce the green firm to extend the market coverage to him/her. This leads to the second proposition of our paper:

Proposition 2 Whenever $b \in[\underline{b}, \tilde{b}]$ and $\gamma \geq \bar{\gamma}$, the unique equilibrium is a monopoly with only the low-green quality firm in the market. Moreover, at this equilibrium the market is uncovered in the range of $\gamma \in\left(\bar{\gamma}, \gamma_{M}\right)$, while it is covered when $\gamma \geq \gamma_{M}$.

Combining Proposition 1 and Proposition 2 leads to the following result:

Proposition 3 In the range of parameters where $b \in[\underline{b}, \tilde{b}]$, there is room in the market for both producers whenever $\gamma<\bar{\gamma}$. At this duopoly equilibrium, the market is uncovered and in the region where $\widetilde{\gamma}<\gamma<\bar{\gamma}$ equilibrium prices are such that $p_{L}^{*}>p_{H}^{*}>0$. On the contrary, whenever $\gamma \geq \bar{\gamma}$, then the high quality but brown producer can no longer stay active in the market which is consequently

\footnotetext{
${ }^{24}$ It is worth remarking that while the high quality firm is no longer active in the market, it still plays a role. Indeed, the candidate equilibrium price $p_{L}^{M}$ depends on the quality gap between variants $\left(q_{H}-q_{L}\right)$.
} 
monopolized by the low quality but green rival. At this monopoly equilibrium, the low quality firm covers the market for any $\gamma \geq \gamma_{M}$, whereas for $\gamma \in\left(\bar{\gamma}, \gamma_{M}\right)$, the monopoly market is uncovered.

The main message conveyed by Proposition 3 is that if the social component of consumption is sufficiently strong, then it may cause the exit of the highbrown quality good from the market. Indeed, in this case consumers value so much the green nature of the goods that they are not willing to buy the brown product, whatever its performance (and thus its hedonic quality) and the market is monopolized by the green firm. Further, note that at equilibrium in the traditional framework, when the market is defined over the interval $[0, b]$, the market is always uncovered because on one hand the consumer of type $\theta=0$ would always get a non-positive utility from buying either good at some positive equilibrium price; on the other hand a firm would get non positive profits selling its good at a nil price to meet the consumer $\theta=0$ if price discrimination were not allowed. On the contrary, for very high values of $\gamma$, here the market can be covered at equilibrium: because of $\gamma$, the lowest willingness to pay can be sufficiently high to induce firm $L$ to offer the variant $q_{L}$ to the whole set of consumers. The social component of consumption introduces a lower bound to the low quality equilibrium price: even the consumer with the lowest willingness to pay is willing to pay a price corresponding to which the low quality firm finds it profitable to cover the market. We can sum up the above considerations as follows. On one hand, for high values of $\gamma$, namely whenever consumers feel the social responsibility to protect the environment, a market-monopolization effect takes place so that only the green firm can stay active in the market. On the other hand, it may well happen that for extremely high values of $\gamma$, the green monopolist extends the market coverage farther than that typically observed in a vertically differentiated setting, thereby inducing a market-coverage effect. The former effect can be a priori detrimental from a welfare viewpoint, as it reduces the number of variants in the market thus possibly raising the equilibrium price of the goods that are still on sale; the latter effect, in contrast, can be welfareenhancing as some consumers which traditionally refrain from buying are now willing to purchase.

\subsection{High-income countries}

Let us consider now the alternative case where $b>\widetilde{b}$. As $\widetilde{b}<\widehat{b}$, we analyse in turn two regions: $b \in] \widetilde{b}, \widehat{b}]$ and $b>\widehat{b}$. Recall also that the ranking between $\widehat{\gamma} \lesseqgtr \widetilde{\gamma}$ is depending on the market size: in particular, it holds that $\widehat{\gamma} \lesseqgtr \widetilde{\gamma} \Longleftrightarrow b \gtreqless \widehat{b}$.

Let us consider first that $b \in] \widetilde{b}, \widehat{b}]$ so that $\widehat{\gamma}>\widetilde{\gamma}$. We will show later that the analysis can be easily extended to the case where $b>\widehat{b}$ without changing the main qualitative results obtained under $b \leq \widehat{b}$.

Taking into account the main ingredients of the analysis performed when $b<\widetilde{b}$, we can easily get that whenever $\gamma \in(0, \widehat{\gamma}]$, the equilibrium is a duopoly with both firms active in the market. Further, in this set of $\gamma$-parameters, the 
market is uncovered at equilibrium. Finally, in line with the result emerged in the previous section, we still find that depending on whether $\gamma \lesseqgtr \widetilde{\gamma}$, a price switch can emerge at equilibrium. In particular, whenever $\gamma<\widetilde{\gamma}$ (resp. $\gamma \geq \widetilde{\gamma}$ ) then the green producer (whose good has a lower performance than the rival) can quote a price $p_{L}^{*}$ such that $p_{L}^{*}<p_{H}^{*}$ (resp. $\left.p_{L}^{*} \geq p_{H}^{*}\right)$ and the price gap $\left(p_{L}^{*}-p_{H}^{*}\right)$ can be intended as a premium for the green firm or symmetrically as a penalty for the dirty producer.

It is worth noting now that the main findings observed in low-income countries cannot be extended tout court to these high-income regions. In particular, we show in the following that, in the range of $\gamma$-parameters where $\gamma>\widehat{\gamma}$, there is still room in the market for both producers. Still, under duopoly the market is now covered at the limit, namely at the equilibrium $\theta_{L}=0$. In particular,

Lemma 3 In the range where $b>\widetilde{b}$, an interior duopoly solution with covered market cannot be sustained at equilibrium when $\gamma>\widehat{\gamma}$.

Proof. When $\gamma>\widehat{\gamma}$ we would obtain that $\theta_{L}<0$, as we know from Lemma 1. We should assume therefore that the demand for the low quality good starts at zero. This means that $x_{L} \equiv \theta_{H}$. Solving the corresponding f.o.c.s for the modified profit functions, the candidate equilibrium prices are $p_{H}^{\prime}=$ $\frac{1}{3}\left[c+2(b-\gamma)\left(q_{H}-q_{L}\right)\right]$ and $p_{L}^{\prime}=\frac{1}{3}\left[2 c+(b+2 \gamma)\left(q_{H}-q_{L}\right)\right]$. Now we can substitute into $\theta_{L}$ and $\theta_{H}$ and check that $\theta_{L}^{\prime}<0<\theta_{H}^{\prime}<b$. Algebraic calculations reveal that $\theta_{L}^{\prime}<0 \Leftrightarrow \gamma>\frac{2 c+(b-\gamma)\left(q_{H}-q_{L}\right)}{3 q_{L}}$, while $\theta_{H}^{\prime}>0 \Leftrightarrow$ $\gamma<b+\frac{c}{2\left(q_{H}-q_{L}\right)}$. However, the two conditions cannot be simultaneously satisfied given that $\frac{2 c+(b-\gamma)\left(q_{H}-q_{L}\right)}{3 q_{L}}>b+\frac{c}{2\left(q_{H}-q_{L}\right)}$, as it can be easily ascertained. Q.E.D.

In such a case, therefore, a duopoly equilibrium with the market covered at the limit becomes the equilibrium candidate. This candidate equilibrium configuration is characterized by a constrained price competition: as the market is covered at the limit, the indifferent consumer $\theta_{L}$ defined in (1) is set equal to zero, and demand functions are defined as $x_{L}=\theta_{H}$ and $x_{H}=b-\theta_{H}$. Accordingly, the equilibrium price of the green good is now $p_{L}^{C}=\gamma\left(q_{H}-q_{L}\right)$. Then, the best reply of the high quality firm implies $p_{H}^{C}=\frac{(b-\gamma)\left(q_{H}-q_{L}\right)}{2}$. Notice that, the optimal price of the brown firm $p_{H}^{C}$ is strictly positive iff $(b-\gamma)>0$. So, whenever the condition $b>\gamma$ is satisfied, there is room in the market for both producers which accordingly cover the market at the limit. Rather, this duopoly structure no longer holds in the case when the social component of consumption turns out to be higher than the highest willingness to pay for the brown good $b$ : whenever $b \leq \gamma$, only the green firm can stay active in the market, the brown producer being evicted. We can thus state the following:

Lemma 4 In the range where $b>\tilde{b}$, at equilibrium the market is monopolized by the green producer whenever $\gamma>b$. 
When the market is monopolized, we know from the analysis developed under $b \leq \tilde{b}$ that, at equilibrium it is profitable for the green producer not to cover the market for any $\gamma<\gamma^{M}$, while covering at the limit in the range of $\gamma \geq \gamma^{M}$. So, in this range of $b$-parameters where $b>\tilde{b}$, one needs to analyse the relationship between $\gamma^{M}$ and $b$ as to conclude about the market coverage. From standard computations, it immediately emerges that $\gamma^{M}>b \Leftrightarrow c>b\left(q_{H}-2 q_{L}\right)$. As $q_{H}$ can be a priori lower than $2 q_{L}$, then $\gamma^{M}>b$ can hold. Accordingly, we can conclude that, for $\gamma \in\left[b, \gamma^{M}\right]$ the monopoly is uncovered, while it is covered at the limit for $\gamma>\gamma^{M}$. So, in line with the findings emerged in the case of low-income countries, we can observe two contrasting effects deriving from $\gamma$ : on one hand, high values of $\gamma$ entails a negative market-monopolization effect such that only the green producer can stay active in the market. On the other hand, in a subset of these values, a positive market coverage effect takes place so that the green producer is induced to cover the market, as even the poorest consumer is willing to pay a sufficiently high price due to the intensity of the social component of consumption. This leads to the following Proposition:

Proposition 4 Whenever $b>\widetilde{b}$, then for any $\gamma \leq b$, the unique equilibrium is a duopoly. At this duopoly equilibrium, the market is uncovered for $\gamma \leq \widehat{\gamma}<b$, while it is covered for $b>\gamma>\widehat{\gamma}$. In contrast, whenever $\gamma>b$, the brown firm cannot be active in the market which is consequently monopolized by the green producer. At this monopoly equilibrium, the market is uncovered for $\gamma \in\left[b, \gamma^{M}\right]$, while it is covered at the limit for $\gamma>\gamma^{M}$.

\section{Low versus High Income countries}

It is worth remarking that while there are similarities between the equilibrium configurations arising for $b \leq \tilde{b}$ and $b>\tilde{b}$, there exist some interesting differences between the two settings.

Indeed, quite intuitively, in both scenarios, as $\gamma$ increases and so the social preference for the environment becomes more important, the green-low quality firm is better off. In particular, as $\gamma$ takes higher and higher values, first the brown-high quality firm can no longer quote a price higher than the price of the green-low quality firm (price switch effect) and then, for high enough values of $\gamma$, the brown firm exits the market that is consequently monopolized by the green firm (market monopolization effect). Finally, for extremely high values of $\gamma$, a positive market coverage effect takes place, with the green producer selling his/her variant to the whole set of consumers in the market. However, whenever the average WTP for quality is rather large or $b>\tilde{b}$, at equilibrium the brown firm gets to stay in the market for a wider range of $\gamma$-parameters than in the opposite case $b \leq \tilde{b}{ }^{25}$ In words, the higher the average income $b$, the higher the social component $\gamma$ that is needed to strand the brown firm out of the market. In a sense, the $b$ and $\gamma$ parameters "work" in opposite directions. Another relevant difference between the two scenarios is that, as long as $b \leq \tilde{b}$,

\footnotetext{
${ }^{25}$ See the proof of the next Proposition.
} 
under duopoly the market is always uncovered and price competition between firms is unconstrained. This statement no longer holds when $b>\tilde{b}$ : in this range of $b$-parameters, for intermediate values of $\gamma$, that is $\widehat{\gamma} \leq \gamma<b$ there exists a duopoly equilibrium with the market covered at the limit where price competition is constrained.

Proposition 5 In the range where $b>\tilde{b}$, the set of $\gamma$-parameters such that a duopoly market arises at equilibrium is larger than in the alternative setting where $b \leq \tilde{b}$.

Proof It suffices to note that the inequality $b>\bar{\gamma}$ is always satisfied with $b$ (resp. $\bar{\gamma}$ ) representing the threshold value such that for $\gamma>b$ (resp. $\gamma>\bar{\gamma}$ ) in the range where $b>\tilde{b}$ (resp. $b \leq \tilde{b})$ the duopoly equilibrium is replaced by a monopoly equilibrium.

Of course, one may wonder under which circumstances $b \gtrless \tilde{b}$. Comparative statics on the relevant thresholds $\underline{b}$ and $\tilde{b}$ show that $\frac{\partial}{\partial q_{H}} \underline{b}=-\frac{c}{\left(q_{L}-q_{H}\right)^{2}}<0$, $\frac{\partial}{\partial q_{H}} \widetilde{b}=-\frac{\left(q_{H}+q_{L}\right) c}{\left(q_{H}-q_{L}\right)^{3}}<0$ and that $\left|\frac{\partial}{\partial q_{H}} \underline{b}\right|<\left|\frac{\partial}{\partial q_{H}} \widetilde{b}\right|$. In words, both $\underline{b}$ and $\tilde{b}$ decrease with $q_{H}$ and $\widetilde{b}$ decreases more than $\underline{b} .{ }^{26}$ This allows us to state that, ceteris paribus, the larger is the hedonic quality gap between variants, the lower is the threshold values and the larger is the set of $b$-parameters satisfying the inequalities $b>\underline{b}$ and $b>\tilde{b}$; also, ceteris paribus, the larger is the hedonic quality gap between variants, the narrower is the range where $\underline{b} \leq b \leq \widetilde{b}$ and the wider is the range where $b>\tilde{b}$, that is, the set of parameters satisfying the condition for the high-income countries scenario to be observed. Along the same rationale, one can observe that: $\frac{\partial}{\partial c} \underline{b}=\frac{\left(2 q_{H}-q_{L}\right)}{\left(q_{H}-q_{L}\right) q_{L}}>0$ and $\frac{\partial}{\partial c} \widetilde{b}=\frac{q_{H}}{\left(q_{L}-q_{H}\right)^{2}}>0$. Further, $\frac{\partial}{\partial c} \underline{b}-\frac{\partial}{\partial c} \widetilde{b}=\frac{\left(2 q_{H}^{2}-4 q_{H} q_{L}+q_{L}^{2}\right)}{\left(q_{L}-q_{H}\right)^{2} q_{L}}>0$ for $q_{H}>1.71 q_{L}$ and $\frac{\partial}{\partial c} \underline{b}-\frac{\partial}{\partial c} \widetilde{b}<0$ for $q_{H} \in\left(q_{L}, 1.71 q_{L}\right)$. Accordingly, we can conclude that ceteris paribus, the larger is the cost gap between variants, the higher is the threshold value and the smaller is the set of $b$-parameters satisfying the inequalities $b>\underline{b}$ and $b>\tilde{b}$. Also, for a quality gap high enough, the larger is the cost gap between variants, the narrower is the range where $\underline{b} \leq b \leq \widetilde{b}$ and the wider is the range where $b>\tilde{b}$, that is, it is more likely that we are in the high-income countries scenario; the opposite holds for $\frac{q_{H}}{q_{L}}$ sufficiently low, that is the larger is the cost gap between variants, the wider is the range where $\underline{b} \leq b \leq \widetilde{b}$ and the narrower is the range where $b>\tilde{b}$, that is, it is more likely that we are in the low-income countries scenario.

\section{Institutions and environmental campaign}

So far, we have characterized the different equilibrium market configurations as a function of consumers' social preferences $\gamma$ relative to their highest WTP for

\footnotetext{
${ }^{26}$ We recall for sake of exposition that $\underline{b} \equiv \frac{c\left(2 q_{H}-q_{L}\right)}{q_{L}\left(q_{H}-q_{L}\right)}, \widetilde{b} \equiv \frac{c q_{H}}{\left(q_{H}-q_{L}\right)^{2}}$
} 
the hedonic quality, $b$. In other words, for different ranges of the parameter $b$, we have depicted consumers' and firms' equilibrium behaviors depending on the value of $\gamma$.

In this section, we wonder whether there is room for information disclosure programs providing consumers with precise data about the environmental quality of goods on sale. By making consumers further aware of their possible contribution to global pollution via dirty shopping, these programs have a direct effect on the value of $\gamma$, thereby possibly changing the market structure at equilibrium. More precisely, we assume that the policy maker can affect the relative concern to environment $\gamma$, by launching an environmental campaign at some costs $s \frac{\gamma^{2}}{2}$, with $s \geq 0$ being the marginal cost of the campaign. ${ }^{27}$ We define the social welfare $S W$ as the sum of consumer surplus $(C S)$, firms' profits $\left(\pi_{L}+\pi_{H}\right)$, environmental damage deriving from global emissions $(D)$, and the costs to sustain the environmental campaign $\left(-s \frac{\gamma^{2}}{2}\right)$. Thus, we can write as follows:

$$
S W=C S+\pi_{L}+\pi_{H}-D-s \frac{\gamma^{2}}{2}
$$

where

$C S=\int_{\max \left\{0, \theta_{L}\right\}}^{\min \left\{b, \theta_{H}\right\}}\left[\left(\theta q_{L}-p_{L}\right)+\gamma\left(q_{H}-q_{L}\right)\right] d \theta+\int_{\min \left\{b, \theta_{H}\right\}}^{b}\left[\left(\theta q_{H}-p_{H}\right)-\gamma\left(q_{H}-q_{L}\right)\right] d \theta$,

and $D=e \cdot x_{H} \cdot{ }^{28}$ It is worth remarking that the emissions coming from the green good so low that they are not taken into account by the social planner in the damage function $D$, regardless of the cost required for increasing consumers' awareness to respect environment.

In order to guarantee the concavity of the welfare function, we make the following assumption on the marginal cost $s$ of the campaign:

\section{Assumption 2.}

$$
s>s_{\min } \equiv \frac{\left(q_{H}-q_{L}\right)\left(12 q_{H}^{3}+19 q_{H}^{2} q_{L}-13 q_{H} q_{L}^{2}+2 q_{L}^{3}\right)}{q_{L}\left(4 q_{H}-q_{L}\right)^{2}} .
$$

In what follows we consider the case of low-income countries and the alternative of high-income countries in turn. In each scenario, comparing the social welfare of the different equilibrium market configurations, we define the relevant emission thresholds that affect the optimal level of the campaign.

\footnotetext{
${ }^{27}$ This cost structure enables to model that it becomes increasingly difficult to sensitize consumers to respect environment.

${ }^{28}$ The environmental damage is usually taken to be quadratic in the level of emissions. Our assumption of a linear environmental damage allows us to simplify calculations and obtain analytically tractable expression. However, the main results of our paper do not change if we consider alternative specifications, even if we would need to resort to numerical simulations.
} 


\subsection{Low income countries}

In the case of low income countries (for any $b \in[\underline{b}, \widetilde{b}]$ ), as long as $\gamma<\bar{\gamma}$, both firms are active in the market and competition is unconstrained. The social welfare at equilibrium as a function of $\gamma$ is thus as follows:

$$
S W^{*}(\gamma)=\pi_{L}^{*}+\pi_{H}^{*}+C S_{L}^{*}+C S_{H}^{*}-e \cdot x_{H}^{*}-s \frac{\gamma^{2}}{2}
$$

with

$$
\begin{aligned}
x_{L}^{*} & =\frac{q_{H}\left[\left(q_{H}-q_{L}\right)\left(2 \gamma q_{H}-q_{L}\right)-c\left(2 q_{H}-q_{L}\right)\right]}{q_{L}\left(4 q_{H}-q_{L}\right)\left(q_{H}-q_{L}\right)}, x_{H}^{*}=\frac{p_{H}^{*}}{\left(q_{H}-q_{L}\right)} ; \\
\pi_{L}^{*} & =\frac{q_{L}}{q_{H}}\left(q_{H}-q_{L}\right)\left(x_{L}^{*}\right)^{2}, \pi_{H}^{*}=\frac{\left(x_{H}^{*}\right)^{2}}{\left(q_{H}-q_{L}\right)}, \\
C S_{L}^{*} & =\int_{\theta_{L}}^{\theta_{H}}\left[\left(\theta q_{L}-p_{L}\right)+\gamma\left(q_{H}-q_{L}\right)\right] d \theta=\frac{\left(x_{L}^{*}\right)^{2}}{2}, \\
C S_{H}^{*} & =\int_{\theta_{H}}^{b}\left[\left(\theta q_{H}-p_{H}\right)-\gamma\left(q_{H}-q_{L}\right)\right] d \theta=\frac{\left(x_{H}^{*}\right)^{2}}{2} \cdot q_{H}\left[(2 b+\gamma)\left(q_{H}^{2}-q_{L}^{2}\right)-c\left(3 q_{H}+2 q_{L}\right)\right]
\end{aligned}
$$

Maximising this welfare function, the Government finds it optimal to set $\gamma$ at some level $\gamma^{*}$ such that:

$$
\gamma^{*}=\frac{q_{H}\left(c q_{H} q_{L}-12 c q_{H}^{2}-3 b q_{L}^{3}+c q_{L}^{2}+11 b q_{H} q_{L}^{2}-8 b q_{H}^{2} q_{L}\right)+e q_{L}\left(4 q_{H}-q_{L}\right)\left(3 q_{H}-q_{L}\right)}{s q_{L}\left(4 q_{H}-q_{L}\right)^{2}-\left(q_{H}-q_{L}\right)\left(12 q_{H}^{3}+2 q_{L}^{3}-13 q_{H} q_{L}^{2}+19 q_{H}^{2} q_{L}\right)} .
$$

It is worth noting that this value $\gamma^{*}$ is strictly positive only when the emissions are sufficiently high, namely

$$
\begin{aligned}
\gamma^{*} & \geq 0 \Longleftrightarrow \\
e & \geq \underline{e}=\frac{q_{H}\left[q_{L} b\left(8 q_{H}-3 q_{L}\right)\left(q_{H}-q_{L}\right)+c\left(3 q_{H}-q_{L}\right)\left(4 q_{H}+q_{L}\right)\right]}{q_{L}\left(q_{L}-4 q_{H}\right)\left(q_{L}-3 q_{H}\right)} .
\end{aligned}
$$

So, given the cost of the campaign, it is socially desirable to affect the consumers' involvement in environmental protection from the social welfare viewpoint only if the damage coming from pollution is rather significant (that is $e \geq \underline{e}$ ). Otherwise, the Government refrains from investing so that $\gamma^{*}=0$, because the cost of the campaign does not compensate the positive effect linked to the emissions reduction. Notice also, that

$$
\begin{aligned}
\gamma^{*} & \leq \bar{\gamma} \Longleftrightarrow \\
e & \leq \bar{e}=\frac{q_{H}\left\{\left(q_{H}-q_{L}\right)^{2}\left(6 q_{H}-q_{L}\right)\left[c-b\left(q_{H}+q_{L}\right)\right]+s\left[c+2 b\left(q_{H}-q_{L}\right)\right]\left(4 q_{H}-q_{L}\right) q_{L}\right\}}{q_{L}\left(q_{H}-q_{L}\right)\left(3 q_{H}-q_{L}\right)^{2}} .
\end{aligned}
$$

Finally, whenever the emissions coming from the brown good are extremely significant, i.e. $e>\bar{e}$, the optimal policy is to reduce as much as possible the 
production of the polluting good so that in this market configuration the social planner sets the optimal level of $\gamma$ at $\gamma^{*}=\bar{\gamma}$.

Accordingly, for values of $e$, such that $e \in(\underline{e}, \bar{e})$, the policy intervention does not change the market structure w.r.t. a laissez-faire case, that is the equilibrium is an unconstrained duopoly. Looking at the equilibrium quantities in this scenario, as one could expect we find that $\partial x_{L}^{*} / \partial \gamma>0$ and $\partial x_{H}^{*} / \partial \gamma<0$. However, more interestingly, total output increases in $\gamma$. This means that the consumer surplus unambiguously increases with this policy instrument. Notice that more traditional instruments like environmental taxation have often pointed out a conflict between environmental protection and market competition because of the distortive effect of taxation on total output. More precisely, the following trade-off emerges in the welfare function as $\gamma$ increases: on the one hand there is a positive effect on the consumer surplus, on the green firm's profit and on the polluting emissions; on the other hand, there is a negative effect on the brown firm's profit and on the cost of the campaign.

We next wonder whether there are values of $e$ such that the policy maker has incentives to further push $\gamma$ so as to reach the monopoly outcome. Recall indeed that for $\gamma>\bar{\gamma}$, the unique equilibrium is a monopoly with only the lowgreen quality firm in the market, the brown firm being no longer active in the market. In this case, i.e., $\gamma \in\left(\bar{\gamma}, \gamma_{M}\right)$, equilibrium quantities and the welfare as a function of $\gamma$ are:

$$
\begin{aligned}
x_{L}^{M} & =\frac{c-b q_{L}-\gamma\left(q_{H}-q_{L}\right)}{2 q_{L}}, \\
\pi_{L}^{M} & =\left(x_{L}^{M}\right)^{2} q_{L}, \\
C S_{L}^{M} & =\frac{\left(x_{L}^{M}\right)^{2}}{2} q_{L}, \\
S W^{M}(\gamma) & =\pi_{L}^{M}+C S_{L}^{M}-s \frac{\gamma^{2}}{2} .
\end{aligned}
$$

Maximising this welfare function, we find the following optimal $\gamma$ level: ${ }^{29}$

$$
\gamma_{M}^{*}=\frac{3\left(q_{H}-q_{L}\right)\left(c-b q_{L}\right)}{3\left(q_{L}-q_{H}\right)^{2}-4 s q_{L}} .
$$

Note however that $\gamma_{M}^{*}<\bar{\gamma}$, showing therefore that, under assumption 2, it is never socially profitable to set a level of $\gamma$ larger than $\bar{\gamma}$. So, $\bar{\gamma}$ represents the maximum investment in environmental campaign carried out by the government. We further check that the government always prefers to leave an $\varepsilon \rightarrow 0$ to the polluting firm, and then still have a duopoly with an amount of emissions that goes to zero instead of letting the green firm monopolize the market.

We gather the above results in the following Proposition.

Proposition 6 Whenever $b \in[\underline{b}, \widetilde{b}]$, the policy maker optimally affects consumers' environmental concern and sets a positive level of $\gamma=\gamma^{*}$ as long as

${ }^{29}$ Given assumption 2, this welfare function in concave in $\gamma$. 
$e \geq \underline{e}$. This optimal level of relative preferences $\gamma^{*}$ increases with the emissions level $e$ and reaches the maximum at $\bar{\gamma}$ for any $e \geq \bar{e}$.

The following picture represents the optimal level of $\gamma$ in the low income countries:

Figure 1 : optimal campaign in the low income country

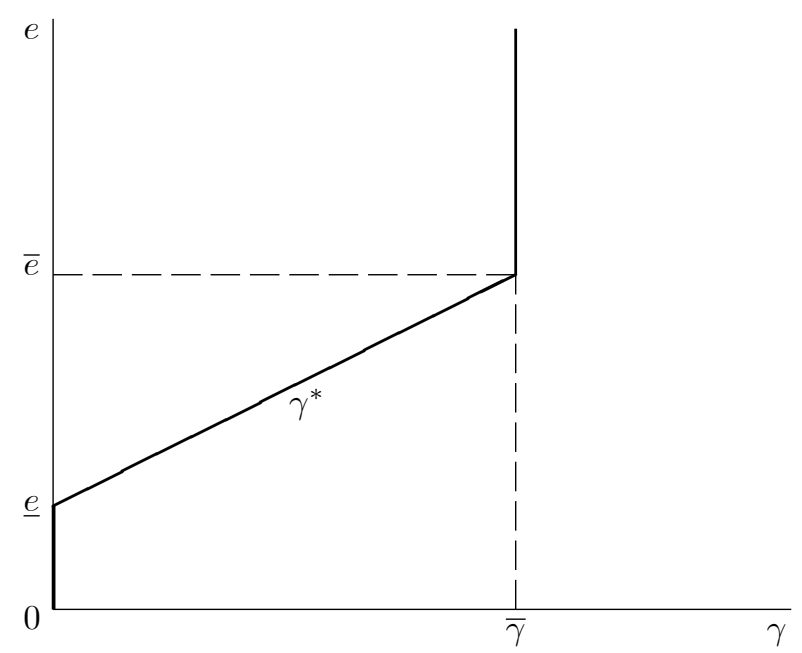

\subsection{High income countries}

In the case of high income countries (for any $b>\widetilde{b}$ ), as long as $\gamma<\widehat{\gamma}$, both firms are active in the market and competition is unconstrained. As in the previous case, in this range of parameters it is optimal to undertake some campaign thereby setting $\gamma=\gamma^{*}$ defined in (13). As before $\gamma^{*}$ takes positive values for $e \geq \underline{e}$. However, we here need to verify that $\gamma^{*}<\widehat{\gamma}$. We find that, this holds when

$e<\bar{e}^{\prime}=\frac{\left(q_{H}-q_{L}\right)\left[b\left(q_{H}-q_{L}\right)\left(q_{H}^{2}-8 q_{H} q_{L}+2 q_{L}^{2}\right)-c q_{H}\left(13 q_{H}-q_{L}\right)\right]+s\left(4 q_{H}-q_{L}\right)\left[2 c q_{H}+b q_{L}\left(q_{H}-q_{L}\right)\right]}{\left(3 q_{H}-q_{L}\right)\left(2 q_{H}^{2}-3 q_{H} q_{L}+q_{L}^{2}\right)}$.

It follows that, when $e \in\left(\underline{e}, \bar{e}^{\prime}\right]$, the optimal investment level is $\widehat{\gamma}>\gamma^{*}>0$, and the social welfare is given by (12). However, in the case when $\gamma$ is driven by the policy maker towards the limit $\widehat{\gamma}$, the resulting market share of the polluting firm is $\varepsilon \rightarrow 0$. In particular, at $\gamma=\widehat{\gamma}$, the social welfare corresponds to the 
following expression:

$$
\begin{aligned}
\left.S W^{*}\right|_{\gamma=\widehat{\gamma}} & =\frac{c^{2} q_{H} \cdot \Lambda-2 c q_{H}\left(q_{H}-q_{L}\right) \cdot \Sigma+b\left(q_{H}-q_{L}\right)^{2} \cdot \Psi}{2\left(2 q_{H}^{2}-3 q_{H} q_{L}+q_{L}^{2}\right)^{2}} \\
\Lambda & =\left[3 q_{H}^{2}-2 q_{L}^{2}-q_{H}\left(q_{L}+4 s\right)\right] \\
\Sigma & =\left[b\left(3 q_{H}^{2}-8 q_{H} q_{L}+5 q_{L}^{2}+2 s q_{L}\right)-e\left(2 q_{H}-q_{L}\right)\right] \\
\Psi & =\left\{b\left[3 q_{H}^{3}-3 q_{H}^{2} q_{L}+3 q_{H} q_{L}^{2}-q_{L}^{2}\left(2 q_{L}+s\right)\right]-2 e\left(2 q_{H}^{2}-3 q_{H} q_{L}+q_{L}^{2}\right)\right\}
\end{aligned}
$$

where the emissions coming from the polluting firm are far from being irrelevant.

We next consider what happens when $e>\bar{e}^{\prime}$. In this case the policy maker may have the incentive to set a $\gamma>\widehat{\gamma}$. Recall from the analysis above that for $\gamma \in(\widehat{\gamma}, b]$, we have a corner solution with covered market and both firms active in the market. Social welfare at equilibrium is as follows:

$$
S W^{* *}(\gamma)=\pi_{L}^{* *}+\pi_{H}^{* *}+C S_{L}^{* *}+C S_{H}^{* *}-s \frac{\gamma^{2}}{2}-e x_{H}^{* *}
$$

with

$$
\begin{gathered}
x_{L}^{* *}=\frac{1}{2}(b+\gamma), x_{H}^{* *}=\frac{1}{2}(b-\gamma) \\
\pi_{L}^{* *}=\frac{1}{2}(b+\gamma)\left(\gamma\left(q_{H}-q_{L}\right)-c\right), \pi_{H}^{* *}=\left(q_{H}-q_{L}\right)\left(x_{H}^{* *}\right)^{2} \\
C S_{L}^{* *}=\left(x_{L}^{* *}\right)^{2} \frac{q_{L}}{2}, C S_{H}^{* *}=\frac{1}{8}(b-\gamma)\left((b-\gamma) q_{H}+2(b+\gamma) q_{L}\right)
\end{gathered}
$$

Note that in this market coverage configuration total output is $x_{L}^{* *}+x_{H}^{* *}=b$, independent of $\gamma$. Thus, in this case, as in the unconstrained duopoly the policy instrument $\gamma$ does not have a distortive effect on market competition. One can easily verify that $\left.S W^{*}\right|_{\gamma=\widehat{\gamma}}=\left.S W^{* *}\right|_{\gamma=\widehat{\gamma}}$, thus verifying the continuity of the social welfare function. Maximising (14) with respect to $\gamma$, we find the following socially optimal value of $\gamma:{ }^{30}$

$$
\gamma^{* *}=\frac{2(c-e)+b\left(q_{H}-q_{L}\right)}{7\left(q_{H}-q_{L}\right)-4 s} .
$$

with $\gamma^{* *} \geq \widehat{\gamma} \Leftrightarrow e>\underline{e}^{C}=\frac{b\left(q_{H}-q_{L}\right)\left[q_{H}^{2}-5 q_{H} q_{L}+2 q_{L}\left(2 q_{L}+s\right)\right]-c\left[5 q_{H}^{2}-q_{L}^{2}-4 q_{H}\left(q_{L}+s\right)\right]}{\left(2 q_{H}-q_{L}\right)\left(q_{H}-q_{L}\right)}$ and $\gamma^{* *}<b \Leftrightarrow e<\bar{e}^{C}=c-b\left(3 q_{H}-3 q_{L}-2 s\right)$ (superscript $C$ indicates the threshold values for the corner case). Note that $\bar{e}^{\prime}<\bar{e}^{C}$. It follows that, in $e \in\left(\bar{e}^{\prime}, \underline{e}^{C}\right]$, the optimal solution $\gamma^{* *}$ is not viable as it would take a value lower than $\widehat{\gamma}$. In such an interval, therefore, the optimal investment is $\widehat{\gamma}$. Finally, for each value of $e>\bar{e}^{C}$, the government decides to set $\gamma=b$. Similarly to the previous scenario, it is never socially desirable to further push $\gamma$ so as to let the green firm to monopolize the market. Quite intuitively, indeed, as $\gamma \rightarrow b$ the market share of the brown firm tends to zero and so the polluting emissions do,

\footnotetext{
${ }^{30}$ Assumption 2 suffices to guarantee the concavity of $S W^{* *}(\gamma)$. More precisely, it is concave when $s>7\left(q_{H}-q_{L}\right) / 4$, but such a value is lower than $\underline{s}$.
} 
however competition is preserved. Moreover, pushing $\gamma$ beyond $b$ would imply to change the market from a duopoly with covered market to a monopoly with uncovered market.

We gather the above results in the following Proposition.

Proposition 7 Whenever $b>\widetilde{b}$, the policy maker optimally affects consumers' environmental concern and sets a positive level of $\gamma=\gamma^{*}$ as long as $e \geq \underline{e}$. This optimal level of relative preferences $\gamma^{*}$ increases with the emission level $e$ until $\gamma=\widehat{\gamma}$ for $e \in\left(\bar{e}^{\prime}, \underline{e}^{C}\right]$. For higher values of $e$, it is socially desirable to further increase $\gamma$ so as to move from an interior duopoly equilibrium to a duopoly equilibrium with the market covered at the limit, that is the optimal $\gamma$ is $\gamma=b$ for any $e \geq \bar{e}^{C}$.

The following picture represents the optimal level of $\gamma$ in high income countries:

Figure 2 : optimal campaign for the high income country

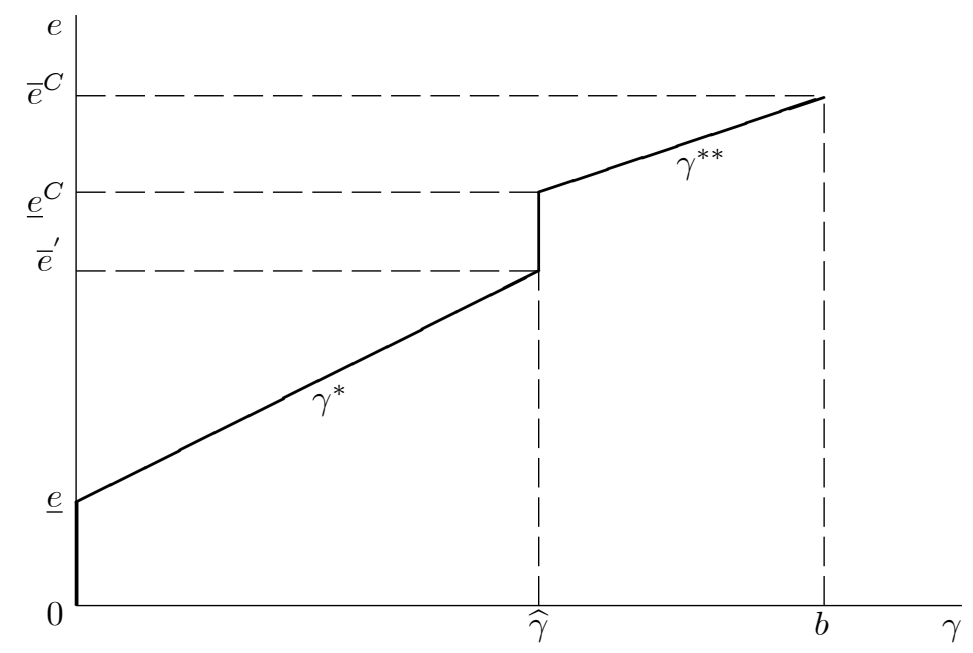

Comparing the two settings of low versus high income countries, similarities and differences emerge. First, in both cases, we can state that the environmental campaign as policy instrument does not generate any trade-off between competition authorities (aiming at fostering competition) and environmental authorities (aiming at reducing pollution): as $\gamma$ increases, one observes the reduction of the emissions but not at the cost of milder competition. Nevertheless, the two settings differ for the predicted maximal investment in environmental campaign: the optimal investment in low-income countries $\bar{\gamma}$ can be lower than the one observed in high income counterparts $\gamma=b$, as $\bar{\gamma} \equiv \frac{q_{H}\left[c+2 b\left(q_{H}-q_{L}\right)\right]}{3 q_{H}^{2}-4 q_{H} q_{L}+q_{L}^{2}}<b \Longleftrightarrow c<\frac{b\left(q_{L}-q_{H}\right)^{2}}{q_{H}}$. At first sight this result is 
counterintuitive, however it reflects the trade-off that characterize our consumer preferences, that is the trade-off between the WTP for the hedonic quality, measured by $b$ and the WTP for the environmental quality measured by $\gamma$. In high income countries (higher values of $b$ ), the WTP for the hedonic quality is higher than for low-income countries: as a result, in order to convince consumers to switch to the green good it is necessary to invest more in the social component of consumption.

\section{Conclusions}

In this paper, we have considered a game between a clean and a dirty producer offering variants complying at different level with the social norm that a green behavior is a byword of good citizenship. We have disentangled the equilibrium properties of the model under the assumption that there exist two sources of differentiation, the performance of the good determining its hedonic quality and the pollution emissions determining its environmental quality. Further, we have assumed that the high (resp. low) hedonic quality variant is less (resp. more) complying with the norm compared with the alternative. So, an environmentally friendly good satisfies the consumers' desire to stand out as good citizens, while frustrating them for the poor performance of the good. We have developed the analysis while taking into account some specific features of the market, in particular consumers' dispersion and average income. The existence of a conflict between the value attributed to the hedonic quality and the positional satisfaction deriving from an environmentally friendly good can change the equilibrium market configuration compared to the traditional setting of vertically differentiated goods: in some circumstance, while both producers are active in the market at equilibrium, the one providing the low hedonic quality good can quote a higher price than the rival because of the green nature of his/her good. Thus, at this duopoly equilibrium, a price switch is observed compared with the typical finding that the high quality good is sold at higher price than the competing variant. Furthermore, we find that whenever the intensity of the relative preferences is sufficiently high, a market-monopolization effect takes place so that only the green firm can stay active in the market, the dirty competitor being pushed away. At this monopoly equilibrium configuration, for extremely high intensity of relative preferences, the green monopolist extends the market coverage farther than that typically observed in a vertically differentiated setting, thereby inducing a market-coverage effect. Finally, we have characterized the optimal campaign to sensitize consumers to damage from pollution, when it is undertaken by a policy maker. We have proved that although the level of investment in campaign is country-specific, in the case when it is socially beneficial to invest in environmental campaign, the policy maker can induce pollution abatement while preserving competition whatever the country where the campaign takes place. 


\section{References}

[1] Akerlof G. (1997). Social Distance and Social Decisions. Econometrica, 65, pp. 1005-1027.

[2] Allcott H. (2011). Social norms and energy conservation. Journal of Public Economics, 95 (9-10), pp. 1082-1095.

[3] Alexopoulos M. and S. Sapp (2006). Exploring the Behavior of Economic Agents: the Role of Relative Preferences. Economics Bulletin, 12 (2), pp. $1-7$.

[4] Ben Elhadj N. and O. Tarola (2014). Relative quality-related (dis)utility in vertically differentiated oligopoly with an environmental externality. Environment and Development Economics, forthcoming.

[5] Ben Elhadj N., J.J. Gabszewicz and O. Tarola (2014). Social awareness and price competition. International Journal of Economic Theory, forthcoming.

[6] Carlsson F, García J.H. and A. Löfgren (2010). Conformity and the demand for environmental goods. Environmental and Resource Economics, 47 (3), pp. $407-421$.

[7] Carrigan, M. and A. Attalla (2001). The Myth of the Ethical Consumer Do Ethics Matter in Purchase Behavior. Journal of Consumer Marketing, 18 (7), pp. 560-577.

[8] Coad A., de Haan, P. and J.S. Woersdorfer (2009). Consumer support for environmental policies: An application to purchases of green cars. Ecological Economics, 68 (2009), pp. 2078-2086.

[9] Conrad K. (2005). Price Competition and Product Differentiation When Consumers Care for the Environment. Environmental \& Resource Economics, 31, pp. 1-19.

[10] Cremer, H. and J. F. Thisse (1994). Commodity Taxation in a Differentiated Oligopoly. International Economic Review, 35, pp. 613-633.

[11] Deltas, G., Harrington, D. R. and M. Khanna (2013). Oligopolies with (Somewhat) Environmentally Conscious Consumers: Market Equilibrium and Regulatory Intervention. Journal of Economics \& Management Strategy, 22, pp. 640-667.

[12] Elster J. (1989). Social Norms and Economic Theory. Journal of Economic Perspectives, 3 (4), pp. 99-117.

[13] Eriksson, C. (2004). Can Green Consumerism Replace Environmental Regulation? a Differentiated Products Example. Resource \& Energy Economics, 26, pp. 281-293. 
[14] European Commission (2011). Attitudes of European citizens towards the environment, Special Eurobarometer 365.

[15] Farhar, B. C. and A. H. Houston (1996). Willingness to Pay for Electricity from Renewable Energy. NREL/TP-460-21216. Golden, CO: National Renewable Energy Laboratory.

[16] Gabszewicz, J.J. and J.F. Thisse (1979). Price Competition, Quality and Income Disparities, Journal of Economic Theory, 20, pp. 340-359.

[17] García-Gallego A. and N. Georgantzís (2009). Market Effects of Changes in Consumers' Social Responsibility. Journal of Economics \& Management Strategy, 18 (1), pp. 235-262.

[18] García-Gallego A. and N. Georgantzís (2010). Good and Bad Increases in Ecological Awareness: Environmental Differentiation Revisited. Strategic Behavior and the Environment, 2011, 1 (1), pp. 71-88.

[19] Goldstein N., R. Cialdini and V. Griskevicius (2008). A Room with a Viewpoint: Using Norm-Based Appeals to Motivate Conservation Behaviors in a Hotel Setting. Journal of Consumer Research, 35, pp. 472-482.

[20] Gupta, S. and G. T. Ogden (2009). To buy or not to buy? A social dilemma perspective on green buying. Journal of Consumer Marketing, 26 (6), pp. 376-391.

[21] Lombardini-Riipinen C. (2005). Optimal Tax Policy under Environmental Quality Competition. Environmental \& Resource Economics. 32 (3), pp. 317-336.

[22] Mantovani and Vergari (2013), Hedonic vs Environmental Quality: Which Policy Can Help in Lowering Pollution Emissions? Working paper 905, Department of Economics, University of Bologna.

[23] McAdams, R. (1992). Relative Preferences, 102 Yale Law Journal 1.

[24] Moraga-Gonzalez, J. L. and N. Padro-Fumero (2002). Environmental Policy in a Green Market. Environmental \& Resource Economics, 22, pp. 419-447.

[25] Mussa, M. and S. Rosen (1978). Monopoly and product quality. Journal of Economic Theory, 18, 301-317.

[26] Nyborg, K., Howarth R.B. and K.A. Brekke (2006). Green Consumers and Public Policy: On Socially Contingent Moral Motivation. Resource and Energy Economics, 28 (4), pp. 351-366.

[27] Ostrom, E. (2000). Collective Action and the Evolution of Social Norms. The Journal of Economic Perspectives, 14 (3), pp. 137-158.

[28] Reichmann, T. (2006). Mixed Motives in a Cournot Game. Economics Bulletin, 4, pp. 1-8. 
[29] Rege, M. (2004). Social Norms and Private Provision of Public Goods. Journal of Public Economic Theory, 6, pp. 65-77.

[30] Rodriguez-Ibeas, R. (2007). Environmental Product Differentiation and Environmental Awareness. Environmental \& Resource Economics, 36, pp. $237-254$.

[31] Salazar, H. A., Oerlemans, L. and S.van Stroe-Biezen (2013). Social influence on sustainable consumption: evidence from a behavioural experiment. International Journal of Consumer Studies, 37 (2), pp. 172-180.

[32] Sartzetakis, E. S., Xepapadeas A. and E. Petrakis (2012). The role of information provision as a policy instrument to supplement environmental taxes. Environmental and Resource Economics, 52, pp. 347-368.

[33] van der Made, A, and L. Schoonbeek (2009). Entry Facilitation by Environmental Groups. Environmental and Resource Economics, 43, pp. 457-472.

[34] Wasik, J. F. (1996). Green marketing and management: a global perspective. Blackwell, Oxford.

[35] Wauthy, X. (1996). Quality Choice in Models of Vertical Differentiation. Journal of Industrial Economics, 44 (3), pp. 345-53.

[36] Weatherell, C., Tregear, A. and J. Allinson (2003), In Search of the Concerned Consumer: UK Public Perceptions of Food, Farming and Buying Local. Journal of Rural Studies, 19 (2), pp. 233-244. 


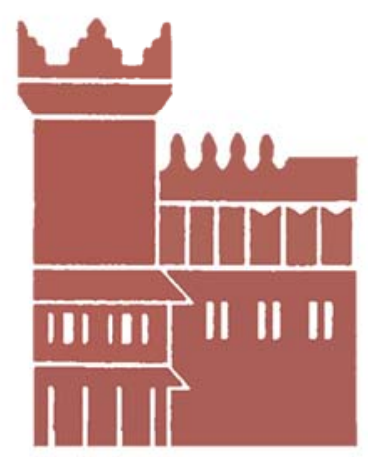

Alma Mater Studiorum - Università di Bologna DEPARTMENT OF ECONOMICS

Strada Maggiore 45

40125 Bologna - Italy

Tel. +39051 2092604

Fax +390512092664

http://www.dse.unibo.it 